\title{
Phase transition behavior of silicone based liquid crystalline polymers
}

\author{
R. N. Jana, ${ }^{1 *}$ H. Bhunia, ${ }^{2}$ C. $I m^{1}$ \\ ${ }^{1 *}$ Department of Chemistry, Institute of Ubiquitous Information Technology and \\ Applications (UbITA), Konkuk University, 1 Hwayang-dong, Gwangjin-gu, Seoul- \\ 143701, South Korea; tel: +82-2-450-3415; fax: +82-2-3436-5382, e-mail: \\ rabindra@konkuk.ac.kr \\ 2Department of Chemical Engineering, Thapar University, Patiala-147004, India.
}

(Received: 31 December, 2008; published: 17 March, 2011)

\begin{abstract}
Phase transition behavior of silicone based liquid crystalline (LC) polymers with variable isotropic transition temperatures $\left(T_{i}\right)$, synthesized from poly(methyl hydrosiloxane), 10-undecenoic acid based crosslinking agent and cholesterol based side chain mesogen, was studied by differential scanning calorimetry (DSC), polarizing optical microscopy (POM), and X-ray diffraction (XRD) measurements. The chemical structure of the mesogenic monomer and the LC polymers were confirmed by Fourier transform infra-red (FT-IR) spectroscopy and ${ }^{1}$ HNMR spectroscopy. DSC studies showed that the glass transition temperatures $\left(T_{g}\right)$ and $T_{i}$ of the LC polymers decreased with increasing proportion of mesogenic crosslinking agent at its low proportion and at its higher proportion $T_{i}$ disappeared completely indicating that the polymeric chains had less chance to orient in the network structure. The results were consistent with the XRD and POM studies.
\end{abstract}

\section{Introduction}

Nowadays, liquid crystal (LC) polymers are used in different areas such as fluorescence paint industries, flat-panel displays, gas detector, actuator and sensor, etc due to their excellent optical properties such as selective reflection of light, thermochromism, and circular dichroism [1-6]. After crosslinking, LC polymers may also be useful in some specific optical applications because of their structure being permanently fixed so that the optical properties become temperature independent [7, 8]. Again lightly crosslinked LC polymers may show the basic features of polymeric elastomers with anisotropic physical properties coming from their LC phases with reversible phase transition during heating and subsequent cooling [9-11]. Thus a series of crosslinked LC polymers, prepared by graft copolymerization, and characterized by DSC and POM, show that at low level of crosslinking agent, the phase behavior of the network polymers does not affect largely; however, at high level of crosslinking agent there may be more drastic influences on LC phases by direct coupling through a shorter or stiffer chain formation between the mesogenic side units and the polymer backbone [12]. The effect of ionic crosslinking agent on phase transition behavior of cholesteric liquid crystalline polymer has also been studied [13]. It is found that the ionic mesogens displayed smectic and cholesteric mesophase in the polymers. The increase of ionic groups in the polymers tends to change the glass transition temperatures $\left(T_{g}\right)$ and clear point a little. The effect of 
spacer length on LC properties is well reported [14-18]. It is found that with an increase in the number of methylene units in the side chains of the polymers, there is an increase in the layer spacing values for the cholesteric liquid crystalline phases as measured by WAXD. Poly(methylhydrosiloxane) based LC polymers with fluorinated mesogens, show smectic LC phase with very wide temperature ranges during heating and cooling cycles [19]. However, the polymers with high fluorine content exhibit smectic-cholesteric phase transition when they are heated. As the polymers contain more fluorinated mesogens, the segregation of the fluorinated segment to the surface may occur at the mesomorphic temperature. The highly ordered lamellar mesogen-siloxane matrix systems may disturb severely by separation of fluorinated mesogens, suggesting the transition from lamellar smectic to cholesteric phase [19]. Thus there are numerous reports on phase transition behavior of different LC polymers, but there are only a limited number of reports on silicone based liquid crystal polymers [20-26] though these polymers are expected to be more thermally stable after several heating and cooling cycles and thus may have potential industrial applications.

So in our present study, we have prepared 1,4-butanediol diundecylenate based flexible crosslinking agent $(\mathrm{M}-1)$ and cholesterol based mesogenic monomer $(\mathrm{M}-2)$ and then $\mathrm{M}-1$ and $\mathrm{M}-2$ are introduced simultaneously into the poly(methylhydrosiloxane) chain. The aim of this work is to investigate the effect of crosslinking agent on phase transition behavior and crystallization behavior of the polymers using differential scanning calorimetry (DSC), polarizing optical microscopy (POM), and X-ray diffraction (XRD) measurements.

\section{Results and Discussion}

\section{Spectral analysis by FT-IR and ${ }^{1} H N M R$}

Fig.1. shows the FT-IR spectra of the crosslinking agent (M-1), mesogenic monomer (M-2) and one LC polymer (e.g., L-1 at the initial stage $(0 \mathrm{~h})$ and after $12 \mathrm{~h}$ of reaction). This shows that $\mathrm{M}-1$ has the characteristic peaks corresponding to $\mathrm{C}-\mathrm{H}$ stretching of vinyl at $3032 \mathrm{~cm}^{-1}, \mathrm{C}-\mathrm{H}$ of methylene at 2921 and $2848 \mathrm{~cm}^{-1}$, alkane ester group (-RCOOR-) at $1710 \mathrm{~cm}^{-1}$ and $\mathrm{C}=\mathrm{C}$ of vinyl at $1466 \mathrm{~cm}^{-1}[10,27]$. The cholesteric monomer (M-2) shows characteristic peaks corresponding to $\mathrm{C}-\mathrm{H}$ stretching of vinyl at $3018 \mathrm{~cm}^{-1}, \mathrm{C}-\mathrm{H}$ of methylene at $2945 \mathrm{~cm}^{-1}, \mathrm{C}=\mathrm{C}$ of vinyl at 1457 and $1369 \mathrm{~cm}^{-1}$. The spectra for the network polymers (e.g. L-1) formed after $12 \mathrm{~h}$ reaction show the complete disappearance of the peaks for the $\mathrm{Si}-\mathrm{H}$ stretching at $2160 \mathrm{~cm}^{-1}$ and vinyl $\mathrm{C}=\mathrm{C}$ stretching at about $1466 \mathrm{~cm}^{-1}$ of the monomers $[10,27]$.

The structures of the crosslinking agent, mesogenic monomer and LCPs are also confirmed from ${ }^{1} \mathrm{H}-\mathrm{NMR}$ analysis. The chemical shifts as observed; $5.70(4 \mathrm{H}, \mathrm{m})$, $5.71(2 \mathrm{H}, \mathrm{m}), 4.81(4 \mathrm{H}, \mathrm{t}), 2.21-1.31(16 \mathrm{H}, \mathrm{t}), 1.98(4 \mathrm{H}, \mathrm{m})$ clearly indicate the formation of crosslinking agent (Fig. 2). Similarly, mesogen has the chemical shift of $3.85(2 \mathrm{H}, \mathrm{m}), 3.71(1 \mathrm{H}, \mathrm{m}), 2.25(2 \mathrm{H}, \mathrm{t}), 0.83(6 \mathrm{H}, \mathrm{m}), 0.65(2 \mathrm{H}, \mathrm{m})$ and LC polymers have a new shift at $1.60(2 \mathrm{H}, \mathrm{m})$ which is due to the methyl hydrogen coming from Si$\mathrm{CH}_{2}$ bond formation (Fig. 2). Thus it is evident that the crosslinking agent (M-1) and mesogenic monomer (M-2) have been successfully incorporated into the poly(methylhydrosiloxane) chain. Moreover, as the yield is more than $95 \%$ in all cases, then almost all M-1 and M-2 molecules have reacted with PMHS. 


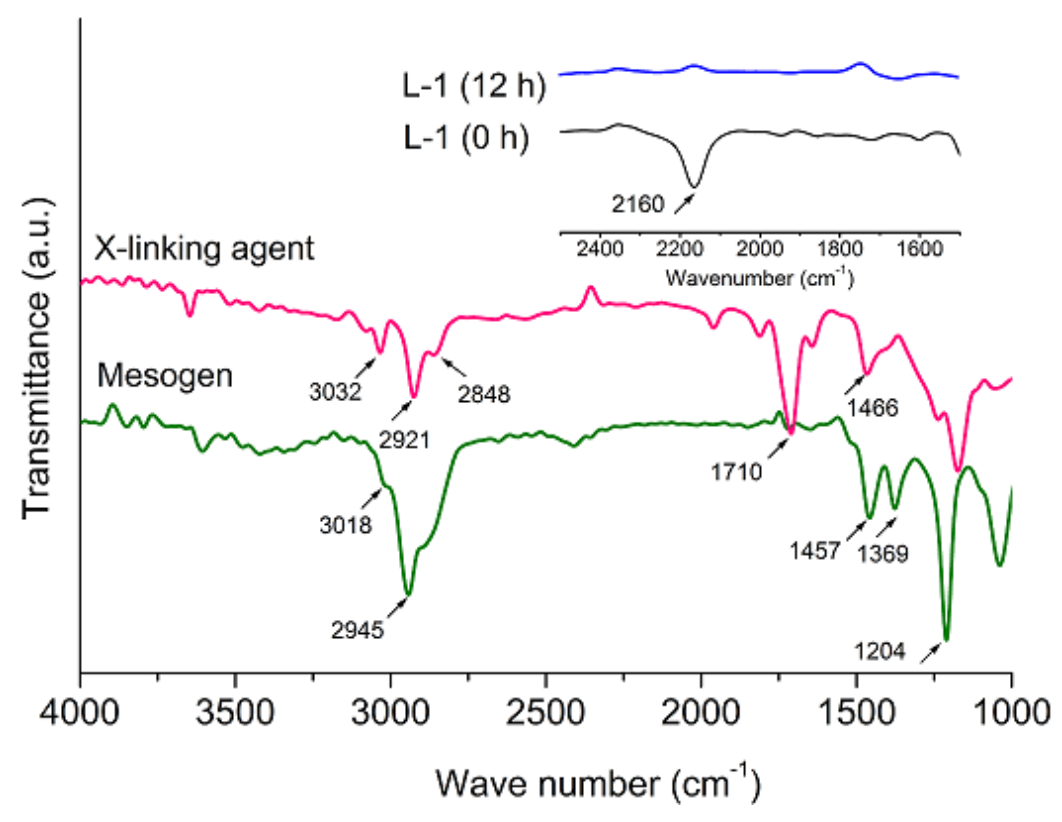

Fig. 1. FT-IR spectra of crosslinking agent $(\mathrm{M}-1)$, mesogenic monomer (M-2) and liquid crystal polymer (LCP-1) at initial stage $(0 \mathrm{~h})$ and after $12 \mathrm{~h}$ of reaction.

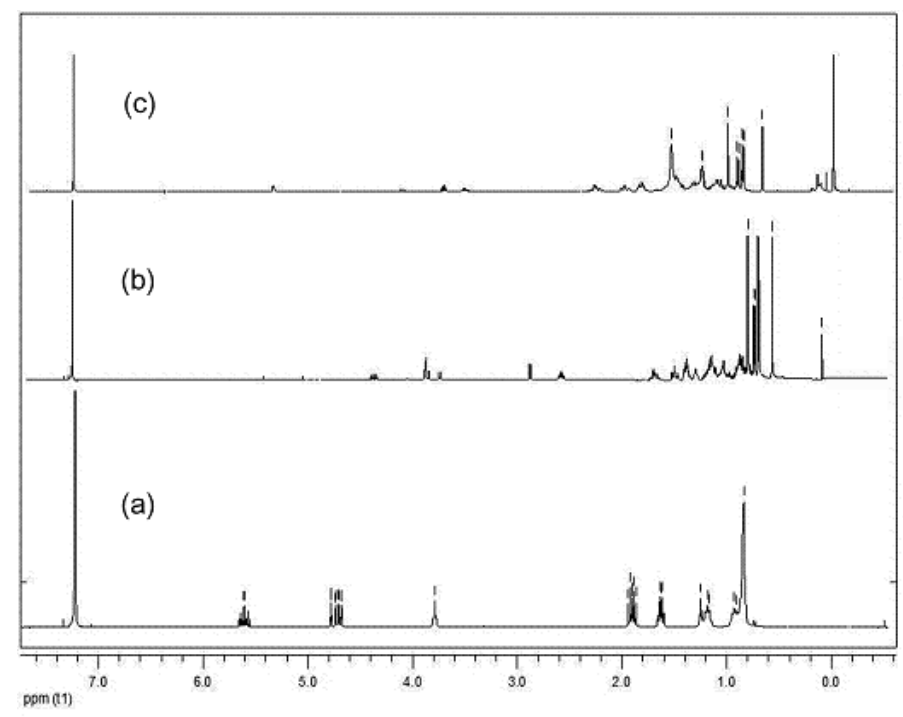

Fig. 2. ${ }^{1} H N M R$ of (a) crosslinking agent, (b) mesogenic monomer and (c) LC polymer $(\mathrm{L}-2)$.

\section{Phase behavior by DSC}

The different transition temperatures of the LC polymers as obtained from their DSC thermograms are reported in Table 1. The polymers with low content of crosslinking agent $(<10.71 \mathrm{~mol} \%)$ (e.g., L-1 L-3) reveal a $\mathrm{T}_{\mathrm{g}}$ near about $40{ }^{\circ} \mathrm{C}$, LC phase transition at about $141{ }^{\circ} \mathrm{C}$ and $\mathrm{T}_{i}$ at about $212^{\circ} \mathrm{C}$ (Fig. 3(a)-(c)). However, L-4 and L5 show only $T_{g}$ and no $T_{i}$ (Fig. 3(d), (e)). It is well known that for side-chain LC polymers, $T_{g}$ is influenced by polymer backbone, mesogenic group, flexible spacer length and crosslinking density. The chemical crosslinking imposes additional constraints on the motion of chain segments, and thus makes $T_{g}$ increase. On the other hand, the flexible chain of the crosslinking agent similar to the plasticization will 
cause $T_{g}$ to decrease. Due to the long flexible chains in both ends of the crosslinking agent for the synthesized polymers, the plasticization of flexible chains was much more significant than the crosslinking limitation on the motion of chain segments [10].

Tab. 1. DSC results of the polymers.

\begin{tabular}{|c|c|c|c|c|c|}
\hline $\begin{array}{l}\text { Sample } \\
\text { Code }\end{array}$ & $\begin{array}{l}\mathrm{T}_{\mathrm{g}} \\
\left({ }^{\circ} \mathrm{C}\right)\end{array}$ & $\begin{array}{l}\mathrm{T}_{\mathrm{m}} \\
\left({ }^{\circ} \mathrm{C}\right)\end{array}$ & $\begin{array}{l}\mathrm{T}_{\mathrm{i}} \\
\left({ }^{\circ} \mathrm{C}\right)\end{array}$ & $\begin{array}{l}\Delta \mathrm{H} \\
(\mathrm{J} / \mathrm{g})\end{array}$ & $\begin{array}{l}\Delta \mathrm{T} \\
\left({ }^{\circ} \mathrm{C}\right)\end{array}$ \\
\hline L-1 & 38.6 & 141.1 & 212.2 & 2.37 & 173.6 \\
\hline L-2 & 37.2 & 141.0 & 209.9 & 1.78 & 172.7 \\
\hline L-3 & 35.5 & 141.0 & 208.6 & 1.50 & 173.1 \\
\hline L-4 & 34.5 & -- & -- & -- & -- \\
\hline L-5 & 34.2 & --- & --- & --- & --- \\
\hline
\end{tabular}

So, with the increasing concentration of crosslinking agent from 3.57 to $21.43 \mathrm{~mol} \%$, $\mathrm{T}_{\mathrm{g}}$ decreases from $38.6^{\circ} \mathrm{C}$ for $\mathrm{L}-1$ to $34.2^{\circ} \mathrm{C}$ for $\mathrm{L}-5$. As the density of crosslinking (M-1) units increased from 3.57 to $10.71 \mathrm{~mol} \%, \mathrm{~T}_{i}$ reduced from $212.2^{\circ} \mathrm{C}$ for $\mathrm{L}-1$ to $208.6^{\circ} \mathrm{C}$ for $\mathrm{L}-3$, and $\mathrm{T}_{i}$ of $\mathrm{L}-4$ and $\mathrm{L}-5$ disappeared for high crosslinking density. At high crosslink density, the plasticizing effect of the flexible chain of the crosslinking agent on $T_{i}$ of liquid crystalline elastomers becomes minor. The enthalpy changes $(\Delta \mathrm{H})$ decreased from $2.37 \mathrm{Jg}^{-1}$ for $\mathrm{L}-1$ to $1.50 \mathrm{Jg}^{-1}$ for $\mathrm{L}-3$. Thus in the LC range, $\mathrm{L}-1$, L-2 and L-3 revealed elasticity and reversible phase transitions on heating and cooling. Whereas, L-4 and L-5 with 17.85 and $21.43 \mathrm{~mol} \%$ of crosslinking agents, respectively, did not show any texture due to high crosslink density.

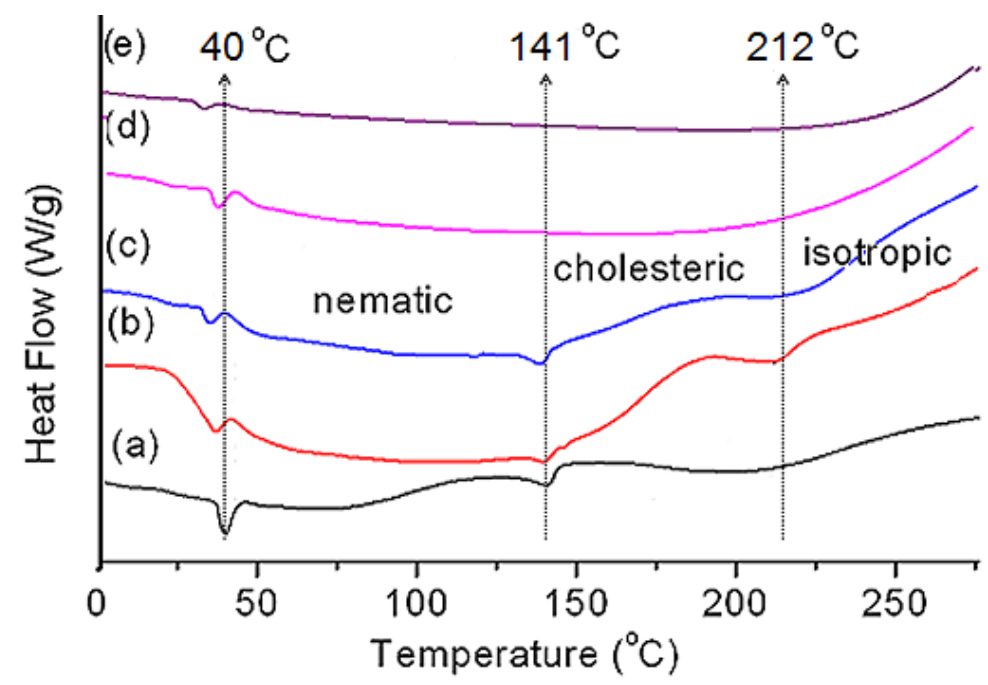

Fig. 3. DSC thermograms of different LC polymers (a) L-1, (b) L-2, (c) L-3, (d) L-4 and (e) L-5.

\section{Crystallization behavior by $X R D$}

The crystallization behavior of the polymers was studied by XRD measurements. It is well known that a smectic liquid crystalline phase shows a sharp and strong peak in the small-angle region and a broad peak in the wide-angle region [10]. But the nematic and cholesteric liquid crystalline phases show only a broad peak in the wide angle region [10]. In our case, no peak was found in the small-angle region but there 
were two broad peaks associated with the lateral packing at about $10.2^{\circ}(2 \theta)$ and $22.5^{\circ}(2 \theta)$ in wide-angle region (Fig. 4.). Thus the formation of nematic and cholesteric phase structure for L-1 to L-3 is confirmed. Again as the peak intensity decreases with increasing the density of crosslinking units in the polymers, it suggests that the crosslinking agent affects largely on the LC order. For the polymers with high crosslink density, there is no such crystalline peak both at for small-angle and wide-angle regions. The high crosslinking leads to the disappearance of isotropic transition of these polymers which is in good agreement with the DSC studies.

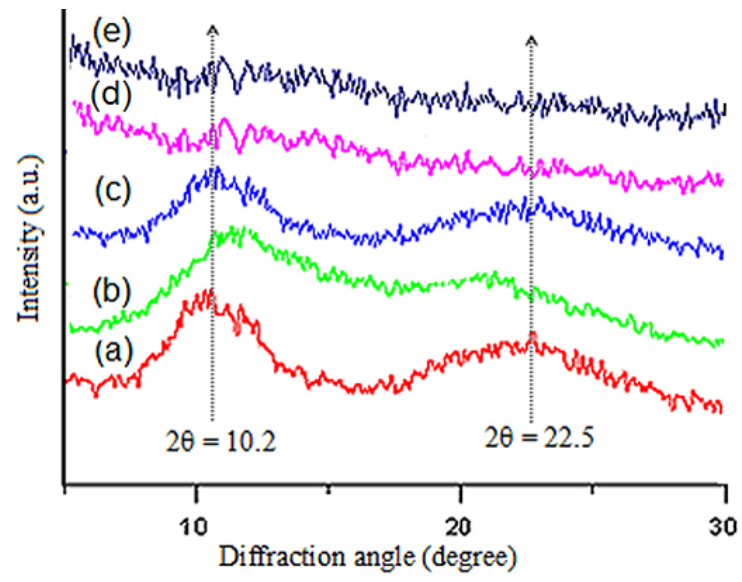

Fig. 4. Wide-angle $X$-ray diffraction of patterns of different liquid crystal polymers, (a) L-1, (b) L-2, (c) L-3, (d) L-4 and (e) L-5..

\section{Phase morphology by POM}

The LC polymers with low crosslink density (e.g., L-1 to L-3) show similar type of phase morphology as observed by POM. So for convenience, the phase morphology only for L-3 has been reported here and it is found that L-3 shows a nematic liquid crystal structure (Fig. 5(a)) with different helicoidal forms, characteristic of cholesteric liquid crystalline polymers. So at room temperature it shows both the nematic and cholesteric textures [28].
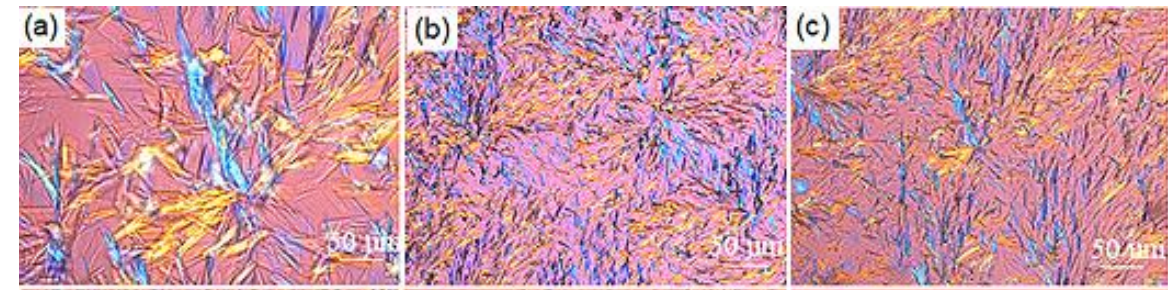

(d)
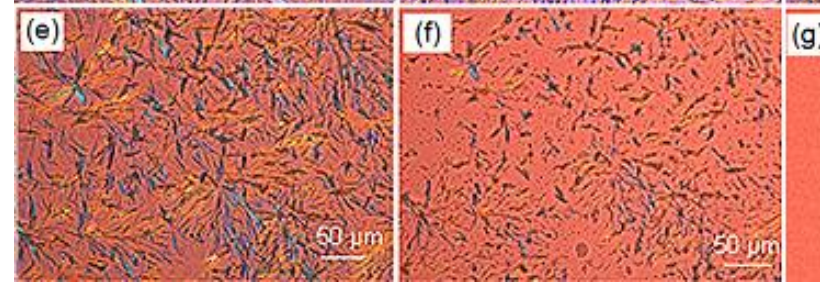

(g)

Fig. 5. POM images of (a) L-3, after $1^{\text {st }}$ heating and subsequent cooling to $25^{\circ} \mathrm{C}$; during second heating for $\mathrm{L}-3$ at different temperatures (b) $142{ }^{\circ} \mathrm{C}$, (c) $206^{\circ} \mathrm{C}$ and (d) $208{ }^{\circ} \mathrm{C}$ and during $1^{\text {st }}$ heating of $\mathrm{L}-4$ at different temperatures (e) $25{ }^{\circ} \mathrm{C}$, (f) $142{ }^{\circ} \mathrm{C}$, (g) $208{ }^{\circ} \mathrm{C}$ and (h) $25^{\circ} \mathrm{C}$, after cooling. 
Now again during second heating as the temperature increases, the nematic phase disappears at about $142{ }^{\circ} \mathrm{C}$ and only cholesteric phase (Fig. 5(b)) remains in the texture until the temperature reaches to $206^{\circ} \mathrm{C}$ (Fig. 5(C)).

Upon further heating up to $208{ }^{\circ} \mathrm{C}$, it changes into an isotropic liquid (Fig. 5(d)). So L1 to L-3 shows a reversible phase transition on heating and cooling. In case of polymers with high crosslinking agent (e.g., L-4, L-5), the phase transition behavior is surprising. It is clear from the POM that the cross polarized light shows different color reflections from the planes of the liquid crystals (Fig. 5(e)) and the crystals are arranged in a zigzag way. As the temperature rises, the crystals start melting (Fig. $5(\mathrm{f}))$ at about $142{ }^{\circ} \mathrm{C}$ and it continues up to $208^{\circ} \mathrm{C}$ (Fig. $5(\mathrm{~g})$ ). On cooling no proper crystallization is found (Fig. 5(h)), this is because at high level of crosslinking agent $(>10.71 \mathrm{~mol} \%)$ permanent set of the polymer network has occurred which restricts the chain movement and the crystallization process. Thus, L-4 and L-5 do not show complete reversible phase transition on cooling which is consistent with the DSC studies though there is a small temperature difference between the reading from DSC and POM due to the human error associated with the POM measurement.

\section{Conclusions}

The different side chain LC polymers containing with a flexible crosslinking agent and a cholesteric monomer have been synthesized successfully. FT-IR and ${ }^{1}$ HNMR spectroscopes confirm the possible structures of the monomers and the synthesized polymers. DSC studies show that $T_{i}$ decreases with an increase in crosslinking agent, though the flexible chain of $M-1$ influences the $T_{g}$ values to lower down. The LC polymers containing low proportion of crosslinking agents (e.g., L-1 L-3) reveal the elasticity and reversible phase transition on heating and cooling whereas highly crosslinked LC polymers do not show this property, as is quite clear from the POM studies. The XRD studies also confirm that the crosslinking agent at its high proportion affects the LC order appreciably.

\section{Experimental}

\section{Materials}

Poly(methylhydrosiloxane) (PMHS, $\mathrm{n}=35$ ); 10-undecenoic acid; allyl bromide; hexachloroplatinic acid $\left(\mathrm{H}_{2} \mathrm{PtCl}_{6}\right)$ (8 wt. \% in water) and cholesterol were purchased from Sigma-Aldrich, USA. 1, 4-Butanediol was supplied by Junsei Chemicals, Japan. All other chemicals were of LR grade reagents.

\section{Characterization}

FT-IR spectroscopic measurements were performed using a Jasco FT-IR 300E with an attenuated total reflectance (ATR) method. ${ }^{1} \mathrm{H}$-NMR characterizations were performed using a Bruker Advanced DMX 500 spectrometer. The samples were prepared in $\mathrm{CDCl}_{3}$ at room temperature. DSC experiments were performed in the temperature range of $0{ }^{\circ} \mathrm{C}$ to $275^{\circ} \mathrm{C}$ on a TA Instruments (Q100) in $\mathrm{N}_{2}$ atmosphere taking sample of about $10 \mathrm{mg}$ encapsulated in aluminum pan. During $1^{\text {st }}$ heating the heating rate was $10^{\circ} \mathrm{C} / \mathrm{min}$ but during $1^{\text {st }}$ cooling and $2^{\text {nd }}$ heating, the cooling and heating rate were of $5{ }^{\circ} \mathrm{C} / \mathrm{min}$ in the both cases. Indium was used as a calibration standard for both the temperature and heat flow scales. The DSC scans for the $1^{\text {st }}$ heating and cooling cycles were discarded. The temperatures corresponding to maxima of the DSC endothermic peaks of the $2^{\text {nd }}$ heating traces were assigned as 
phase transition temperatures. The midpoint of the heat capacity stepwise increase was taken as the glass transition temperature. Wide-angle X-ray diffraction studies using monochromatized $\mathrm{CuK}_{\alpha}$ radiation and a nickel filter was carried out in X-ray diffractometer (Bruker AXS). The diffraction was recorded in the range of $5^{\circ}(2 \theta)$ to $30^{\circ}(2 \theta)$ at a scanning speed of $5 \%$ min. Polarized optical microscope (Eclipse LV 100 POL) from Nikon Corporation, Tokyo, Japan, equipped with a hot stage (LTS 350) from Linkon Scientific Instruments Ltd, England, UK, was used to observe visual textures and phase transition temperatures for analyzing the mesomorphic properties of the liquid crystalline monomers and polymers. The samples used for POM analysis were sandwiched between two glass cover slips and melted on a hot stage at $250^{\circ} \mathrm{C}$, care being taken to avoid cover slip sliding over that would lead to void formation, and subsequently cooled to room temperature. The rate of heating and cooling were selected similar to the DSC studies.

\section{Synthesis of crosslinking Agent (M-1)}

About $1 \mathrm{ml}$ concentrated sulfuric acid was added to the mixture of about $22.08 \mathrm{~g}$ $(0.12 \mathrm{~mol})$ of undecylenic acid and $5.9 \mathrm{~g}(0.05 \mathrm{~mol})$ of 1,4 -butanediol dissolved in 30 $\mathrm{ml}$ benzene. After the mixture was mixed uniformly, it was refluxed at $120^{\circ} \mathrm{C}$ for $8 \mathrm{~h}$, and the mixture was poured into $200 \mathrm{ml}$ of water. After removing the water layer, the oil layer was neutralized with $2 \% \mathrm{NaHCO}_{3}$ to $\mathrm{pH} 7$, washed several times with distilled water, and dried with anhydrous $\mathrm{Na}_{2} \mathrm{SO} 4$. Then the distillate of crude product, collected at $175{ }^{\circ} \mathrm{C}$ under $3 \mathrm{~mm} \mathrm{Hg}$ pressure gave the transparent liquid as the monomer $\mathrm{M}-1$ (Scheme 1).

\section{Synthesis of mesogenic monomer (M-2):}

About $19.3 \mathrm{~g}(0.05 \mathrm{~mol})$ of cholesterol was dissolved in $80 \mathrm{ml}$ of chloroform, followed by the drop wise addition of $30 \mathrm{ml}$ of an aqueous solution of potassium hydroxide (30 wt \%). Then $6.0 \mathrm{~g}(0.05 \mathrm{~mol})$ of allyl bromide was slowly dropped into the mixture. After the mixture was reacted at room temperature for $2 \mathrm{~h}$ and was refluxed at $90{ }^{\circ} \mathrm{C}$ for $4 \mathrm{~h}$, it was cooled to room temperature and poured into $300 \mathrm{ml}$ of deionized water to get a transparent yellow solution.

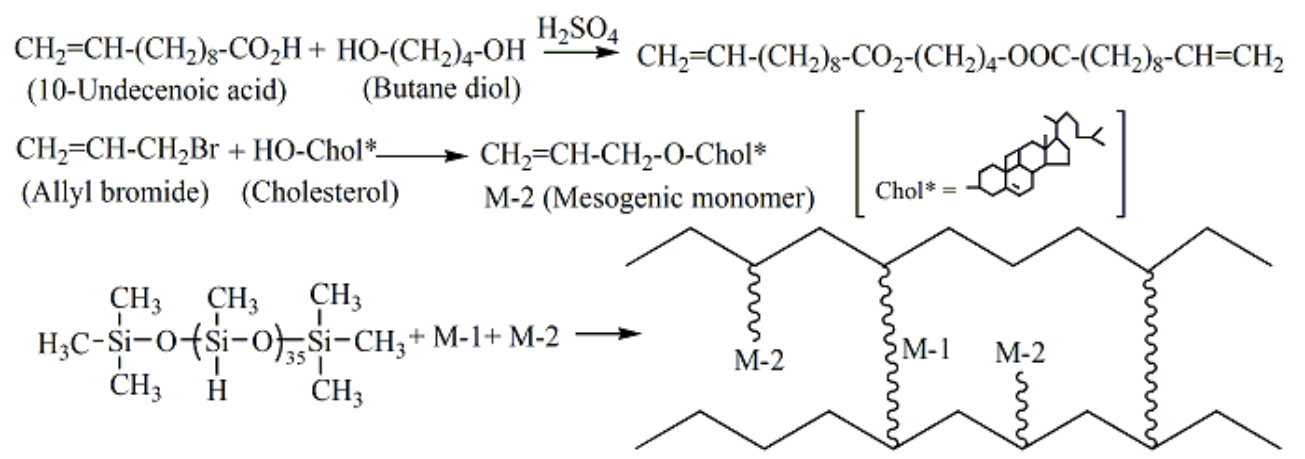

Scheme 1. Synthesis route for crosslinking agent, mesogenic monomer and LCPs.

Afterwards, the organic phase was extracted with $50 \mathrm{ml}$ of diethyl ether three times. To the aqueous phase, $80 \mathrm{ml}$ of $30 \%$ hydrochloric acid solution was added, leading to a white precipitation which on further recrystallization from ethanol gave the desired product (Scheme 1). 


\section{Synthesis of polymers}

The polymers were prepared by a graft reaction, in which the crosslinking agent $\mathrm{M}-1$ and the mesogenic monomer M-2 were simultaneously attached to the highly flexible poly(methylhydrosiloxane) chain via a hydrosilation reaction. For convenience, the synthesis procedure for L-1 polymer was only reported here, however, the other polymers were made, following the same procedure as for $L-1$, with different proportions of crosslinking agent varying from $3.57 \mathrm{~mol} \%$ to $21.43 \mathrm{~mol} \%$ (Table 2). For synthesis of L-1 polymer, the crosslinking monomer M-1 $(0.15 \mathrm{~g}, 0.25 \mathrm{mmol})$ was taken in $50 \mathrm{ml}$ dry toluene, then mesogenic monomer $\mathrm{M}-2(2.45 \mathrm{~g}, 5.75 \mathrm{mmol})$, and PMHS $(2.450 \mathrm{~g}, 1.00 \mathrm{mmol})$ were added to that solution with continuous stirring. The reaction mixture was heated to $65{ }^{\circ} \mathrm{C}$ under nitrogen, and then $2 \mathrm{ml}$ of $0.5 \mathrm{wt} \%$ $\mathrm{H}_{2} \mathrm{PtCl}_{6} / \mathrm{THF}$ catalyst solution was injected.

Tab. 2. Composition of silicone base LC polymers.

\begin{tabular}{cccccc}
\hline $\begin{array}{c}\text { Sample } \\
\text { Code }\end{array}$ & $\begin{array}{c}\text { PMHS } \\
(\mathrm{mmol})\end{array}$ & $\begin{array}{c}\mathrm{M}-1 \\
(\mathrm{mmol})\end{array}$ & $\begin{array}{c}\mathrm{M}-2 \\
(\mathrm{mmol})\end{array}$ & $\begin{array}{c}\mathrm{M}-1 \\
(\mathrm{~mol} \%)\end{array}$ & $\begin{array}{c}\text { Yield } \\
(\%)\end{array}$ \\
\hline L-1 & 1.00 & 0.25 & 5.75 & 3.57 & 95 \\
L-2 & 1.00 & 0.50 & 5.50 & 7.14 & 97 \\
L-3 & 1.00 & 0.75 & 5.25 & 10.71 & 97 \\
L-4 & 1.00 & 1.25 & 4.75 & 17.85 & 96 \\
L-5 & 1.00 & 1.50 & 4.50 & 21.43 & 96 \\
\hline
\end{tabular}

The reaction was kept at $65{ }^{\circ} \mathrm{C}$ under nitrogen until the $\mathrm{Si}-\mathrm{H}$ absorption peak of PMHS at $2160 \mathrm{~cm}^{-1}$ disappeared. It took about $12 \mathrm{~h}$ to complete the reaction. Then the elastomers were carefully deswollen with methanol to remove the excessive monomers and the catalyst fragments and then dried under vacuum over night. Deswelling in methanol and subsequent vacuum drying were repeated several times until to get a constant weight of the polymers so that almost all the impurities were eliminated from the polymers.

\section{Acknowledgements}

This research was supported by the $2009 \mathrm{KU}$ Brain Pool Program of Konkuk University, South Korea, and Seoul R \& BD Program (10848).

\section{References}

[1] Du, B. G.; Hu, J.S.; Zhang, B. Y.; Xiao, L. J.; and Wei, K. Q. J.Appl.Polym.Sci. 2006, 102, 5559 .

[2] Liu, J.; Ni, P.; Qiu, D.; Hou, W.; Zhang, Q. Reactive Funct.Polym., 2007, 67, 416.

[3] Bobrovsky, A.; Shibaev, V. Polymer, 2006, 47, 4310.

[4] Bobrovsky, A.; Shibaev, V. J.Photochem.Photobio. A: Chem., 2005, 172, 140.

[5] Zhao, Y.; Chen, J.; Zeng, E.; Hu, X.; Liu, A.; Dong, Y. Carbo. Polym., 2008, 74, 828.

[6] Liu, J. H.; Wang, Y. K.; Chen, C. C.; Yang, P. C.; Hsieh, F. M.; Chiu, Y. H. Polymer, 2008, 49, 3938.

[7] Stohr, A.; Strohriegl, P. Macromol.Chem.Phys., 1998, 199, 751.

[8] Meng, F.; Zhang, B.; Liu, L.; Zang, B. Polymer, 2003, 44, 3935.

[9] Gebhard, E.; Zentel, R. Macromol. Chem. Phys., 2000, 201, 902. 
[10] Jia, Y. G.; Zhang, B. Y.; Tian, M.; Wei, K. Q. Reactive Funct. Polym., 2005, 63, 55.

[11] Ganicz, T.; Stańczyk, W. Materials, 2009, 2, 95.

[12] Zhang, B. Y.; Liu, L. M.; Yao, D. S.; Zhang, L. F. Colloid Polym. Sci., 2005, 283, 1143.

[13] Zhang, B. Y.; Meng, F. B.; Tian, M.; Xiao, W. Q. Reactive. Funct. Polym., 2006, 66, 551.

[14] Huang, B.; Ge, J. J.; Li, Y.; Hou, H. Polymer, 2007, 48, 264.

[15] Ravikrishnan, A.; Sudhakara, P.; Kannan, P. Polym.Degrad.Stab., 2008, 93, 1564.

[16] Han, X.; Zhang, S.; Shanks, R. A.; Pavel, D. Reactive Funct. Polym. 2008, 68, 1097.

[17] Zhu, X. Q.; Liu, J. H.; Liu, Y. X.; Chen, E. Q. Polymer, 2008, 49, 3103.

[18] Bagheri, M.; Pourmoazzen, Z. Reactive \& Funct. Polym., 2008, 68, 507.

[19] Meng, F. Lian, J.; Zhang, B.; Sun, Y. Eur.Polym.J., 2008, 44, 504.

[20] Li, X.; Goh, S. H.; Lai, Y. H. Liq. Cryst. 2002, 29, 675.

[21] Li, X.; Goh, S.H.; Lai, Y.H.; Si, X.C. Liq. Cryst. 2001, 28, 1527.

[22] Li, X.; Goh, S.H.; Lai, Y.H. Liq. Cryst. 2003, 30, 811.

[23] Li, X.; Goh, S.H. Wee, A.T.S. Polymer 2000, 41, 6563-6571.

[24] Hu, J. S.; Zhang, B.; Liu, L. M.; Meng, F. B. J.Appl.Polym.Sci. 2003, 89, 3944.

[25] Zhi, J.; Zhang, B.; Shi, G. J.Appl.Polym.Sci. 2002, 85, 2155.

[26] Jia, Y.; Zhang, B.; Feng, Z.; Guan, Y. Eur.Polym.J. 2003, 39, 1701.

[27] Jia, Y. G.; Zhang, B. Y.; Sun, Q. J.; Chang, H. X. Colloid.Polym.Sci., 2004, 282, 1077.

[28] Wang, Y.; Zhang, B.; He, X.; Wang, J. W. Colloid. Polym. Sci. 2007, 285, 1077. 